This item was submitted to Loughborough's Research Repository by the author.

Items in Figshare are protected by copyright, with all rights reserved, unless otherwise indicated.

\title{
Fabrication and characterisation of slim flat vacuum panels suitable for solar applications
}

PLEASE CITE THE PUBLISHED VERSION

http://dx.doi.org/10.18086/eurosun.2014.16.02

\section{PUBLISHER}

(C) 2015. The Authors. Published by International Solar Energy Society

\section{VERSION}

VoR (Version of Record)

\section{PUBLISHER STATEMENT}

This work is made available according to the conditions of the Creative Commons Attribution-NonCommercialNoDerivatives 4.0 International (CC BY-NC-ND 4.0) licence. Full details of this licence are available at: https://creativecommons.org/licenses/by-nc-nd/4.0/

\section{LICENCE}

CC BY-NC-ND 4.0

\section{REPOSITORY RECORD}

Arya, Farid, Trevor Hyde, Paul Henshall, Philip C. Eames, Roger Moss, and Stan Shire. 2019. "Fabrication and Characterisation of Slim Flat Vacuum Panels Suitable for Solar Applications". figshare. https://hdl.handle.net/2134/19239. 


\title{
Fabrication and Characterisation of Slim Flat Vacuum Panels Suitable for Solar Applications
}

\author{
Farid Arya ${ }^{1}$, Trevor Hyde ${ }^{1}$, Paul Henshall ${ }^{2}$, Phillip Eames ${ }^{2}$, Roger Moss ${ }^{3}$ and Stan Shire ${ }^{3}$ \\ ${ }^{1}$ Center for Sustainable Technologies, University of Ulster, UK \\ ${ }^{2}$ Centre for Renewable Energy Systems Technology, Loughborough University, UK \\ ${ }^{3}$ School of Engineering, University of Warwick, UK
}

\begin{abstract}
The concept of providing an evacuated space between two planar surfaces and exploiting its thermal properties was initially proposed in 1913 for window applications in buildings (Zoller, 1913). Since then a number of designs for the fabrication of evacuated windows have been proposed investigating sealing methods for the periphery of the glass panes and methods of maintaining the separation of the glass panes under the influence of atmospheric pressure (Collins et al., 1995). Evacuated windows have also been used in solar applications by creating a vacuum (less than $0.01 \mathrm{mbar}$ ) around a solar absorber to reduce the convective heat losses resulting in higher efficiencies. Maintaining the vacuum pressure over the life time of the panel is challenging. This is largely dependent on the materials used in the fabrication process. Forming a durable hermetic seal around the periphery of the vacuum enclosure is particularly crucial. In this work prototypes of flat vacuum panels with solar applications are fabricated and tested. Indium is used as a sealing material to create a hermetic seal around the periphery the panel. A heat transmission of $0.86 \mathrm{Wm}^{-2} \mathrm{~K}^{-1}$ in the centre of the vacuum panel has been achieved for a $0.4 \mathrm{~m}$ by $0.4 \mathrm{~m}$ panel.
\end{abstract}

\section{Introduction}

Creating a vacuum space around a flat solar absorber thereby taking advantage of its high thermal insulation properties has been investigated by many researchers. An evacuated flat-plate solar collector was proposed and simulated in 1970s (Eaton and Blum, 1975). It was shown that a pressure of 1-33mbar eliminated the convective heat transfer from the absorber to the surrounding glass panes given a separation of $150 \mathrm{~mm}$ between the glass panes and the absorber. Evacuated flat solar collectors progressed to the point where it was possible to deliver steam at temperatures of up to $150^{\circ} \mathrm{C}$ at efficiencies of nearly $50 \%$ (Benz and Beikircher, 1999). The main challenges in the fabrication of this kind of solar collectors is creating a hermetic seal around the periphery of the glass panes which must be strong enough to withstand all types of stresses caused by atmospheric pressure and thermal expansion/contraction over its life time. In addition, a method needs to be employed to maintain the separation of the glass panes under the influence of the atmospheric pressure.

Prototypes of slim flat vacuum panels suitable for use in solar thermal collectors as schematically shown in Fig. 1 were fabricated and their thermal performance characterized using a guarded hot box calorimeter. The wide vacuum space enables the integration of a wide solar absorber as schematically shown in Fig. 2. The vacuum space provides a high level of thermal insulation around the solar absorber which reduces heat losses from the absorber by conduction and convection thereby increasing the efficiency of the solar collector. However, a method of maintaining a gap between the solar absorber and the glass panes and spacers must be developed to avoid thermal bridges.

The fabricated panel as shown in Fig. 3 consisted of two glass panes hermetically sealed around their periphery to an aluminium spacer creating a cavity between the glass panes which is to be evacuated. Using ultrasonic soldering techniques, indium metal is used to create a hermetic seal at a temperature well below 
$200^{\circ} \mathrm{C}$ (Hyde et al., 2000). Hard low emittance coatings are deposited on the internal glass surfaces to minimise radiative heat losses. Arrays of stainless steel support pillars are set between the glass panes to prevent the panes from collapsing under the influence of atmospheric pressure. The sealing process is undertaken in vacuum to prevent oxidation of the sealing materials. After the formation of the edge seal, the evacuation of the panel is the key to achieving a high level of vacuum and consequently a high level of thermal insulation. Heat flow between the glass panes of the flat vacuum panels remote from the edge seal can occur due to radiation between the internal surfaces, thermal conduction through residual gas in the evacuated gaps and thermal conduction through the support pillars.

When the required vacuum pressure is achieved, applying a temperature difference between the glass panes will allow heat leaks through the support pillars and the peripheral edge seal in vacuum panel to be detected using infra-red thermography. The thermal insulation of the vacuum panels can be accurately determined using the guarded hot box calorimeter shown in Fig. 4.

\section{Fabrication process}

Fabricating flat vacuum panels requires the formation of a leak-free seal around its perimeter. This is accomplished by bonding two glass panes to a $10 \mathrm{~mm}$ thick aluminum spacer (6082 grade) with indium using an ultrasonic soldering process and the application of a secondary seal to prevent moisture ingress from occurring. This technique enables the flat vacuum panels to be produced in a vacuum oven at a temperature of less than $160^{\circ} \mathrm{C}$.

Prior to the fabrication, a hole is drilled in one of the glass panes for evacuation purposes near the corner. After the edge seal formation and subsequent cool down of the panel, a turbo molecular vacuum pump is connected to the glazing via a pump-out cup which uses an O-ring seal on the upper glass pane around the pump out hole. During evacuation the panel assembly is re-heated to $150^{\circ} \mathrm{C}$ in a bake-out oven to outgas the internal surfaces. After the evacuation is completed the pump-out hole is sealed using a glass cover disc precoated in indium. During sealing of the pump-out hole an internal vacuum pressure down to $8 \times 10^{-6} \mathrm{mbar}$ was achieved; this method has been described in detail elsewhere (Zhao et al., 2007). During evacuation atmospheric pressure induces large stresses across the vacuum panel particularly in the region of the edge seal and the support pillars. The edge seal must be strong enough to withstand these stresses. A fabricated panel as shown in Fig. 3 comprises two $4 \mathrm{~mm}$ thick glass panes, sized $0.4 \mathrm{~m}$ by $0.4 \mathrm{~m}$, with low-e coatings (emittance of 0.16 ) on the glass surfaces facing the vacuum gap. The separation of the panes which would otherwise touch under the influence of atmospheric pressure is maintained by arrays of stainless steel (grade 304L) support pillars. The pillars are $10.2 \mathrm{~mm}$ high and $6 \mathrm{~mm}$ in diameter and spaced at $50 \mathrm{~mm}$ intervals on a regular square Cartesian grid. To reduce the contact area and minimize the thermal conduction between the pillars and the glass panes the pillars are made in tubular form.

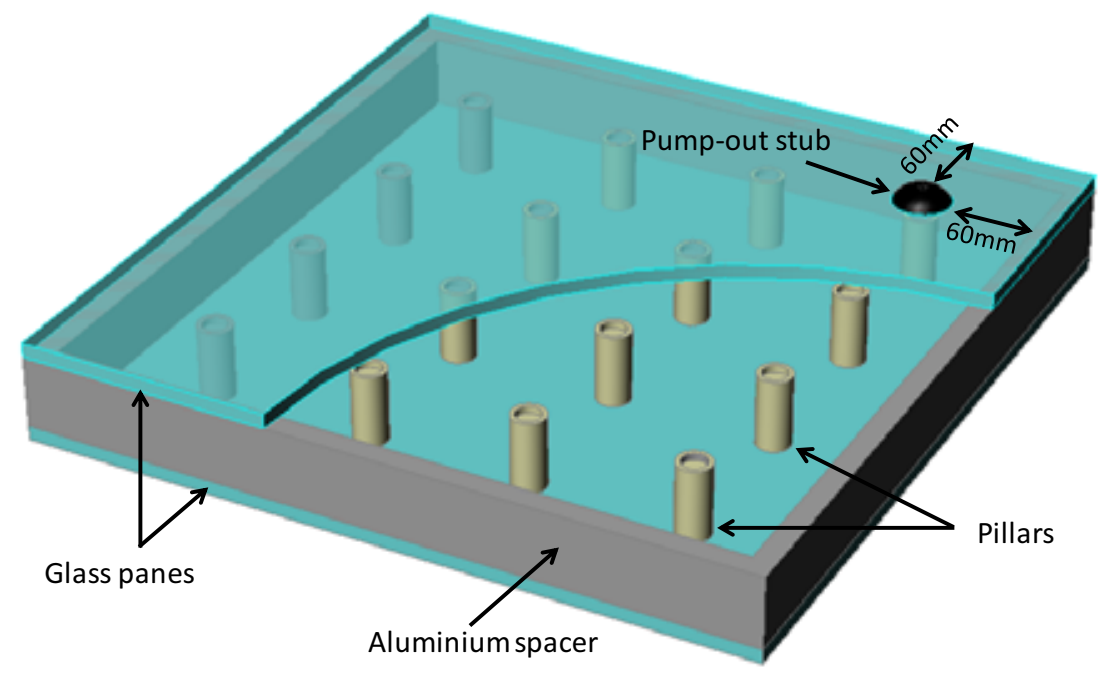

Fig. 1: Schematic diagram of a flat vacuum panel 


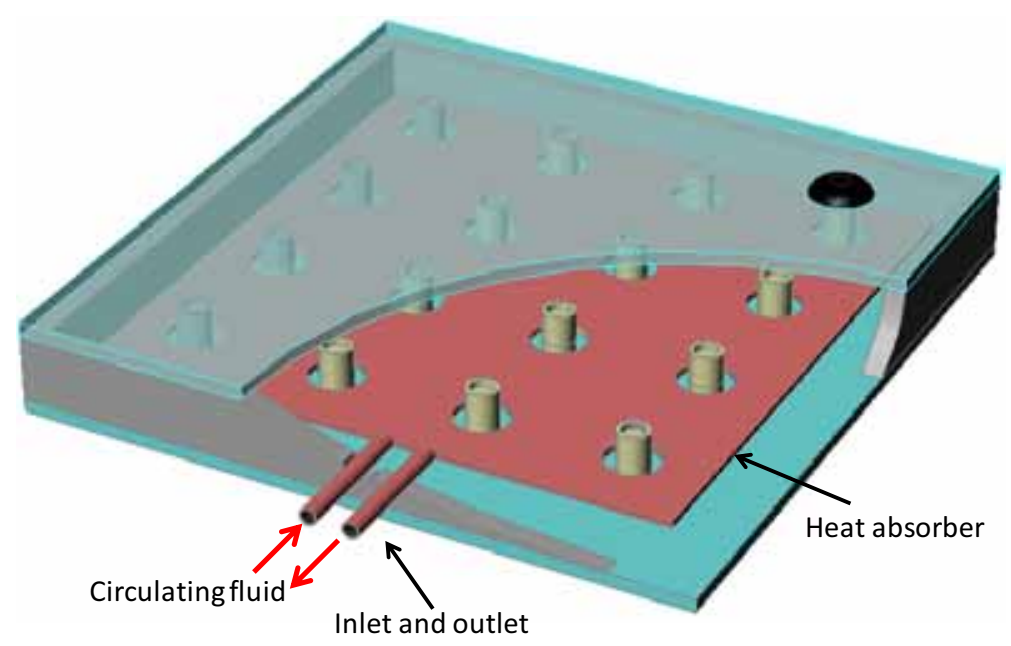

Fig. 2: Schematic diagram of a flat vacuum panel

The main stages of the manufacturing process of the flat vacuum panel used in this work are outlined below:

1) Cleaning glass panes using acetone and isopropanol, and initial bake-out in a conventional oven at $200^{\circ} \mathrm{C}$.

2) Deposition of a thin $10 \mathrm{~mm}$ wide layer of indium around the periphery of the glass panes using an ultrasonic soldering iron to promote good bonding between the indium and the glass.

3) Polishing the pillars and aluminium spacer using a fine emery paper and treating them using Hydrochloric acid (33\%).

4) Deposition of a thin layer of indium on the top and bottom side of the aluminum spacer using the ultrasonic soldering iron.

5) The support pillars are located on the lower glass pane spaced at $50 \mathrm{~mm}$ intervals on a regular square Cartesian grid.

6) The aluminum spacer is placed on the lower glass pane so that the indium layers are aligned.

7) The upper glass pane is placed on the aluminum spacer and the assembly is introduced into a vacuum oven.

8) The vacuum oven pressure is reduced to $10^{-7} \mathrm{mbar}$ and initial out-gassing is performed.

9) The temperature of the vacuum oven is increased to $160^{\circ} \mathrm{C}$ at which the seal is formed by indium reflow.

10) The vacuum chamber is allowed to cool to room temperature.

11) The sample is removed from the oven and connected to a turbo molecular vacuum pump through a pump-out device, and the evacuation process is started.

12) The panel is heated up to $150^{\circ} \mathrm{C}$ and maintained at that temperature for 7 hours after which the pump-out hole is sealed using a glass cover disc.

13) The sample is cooled to room temperature, disconnected from the pump-out device and then a secondary adhesive seal is applied to protect the indium bond from moisture ingress. 


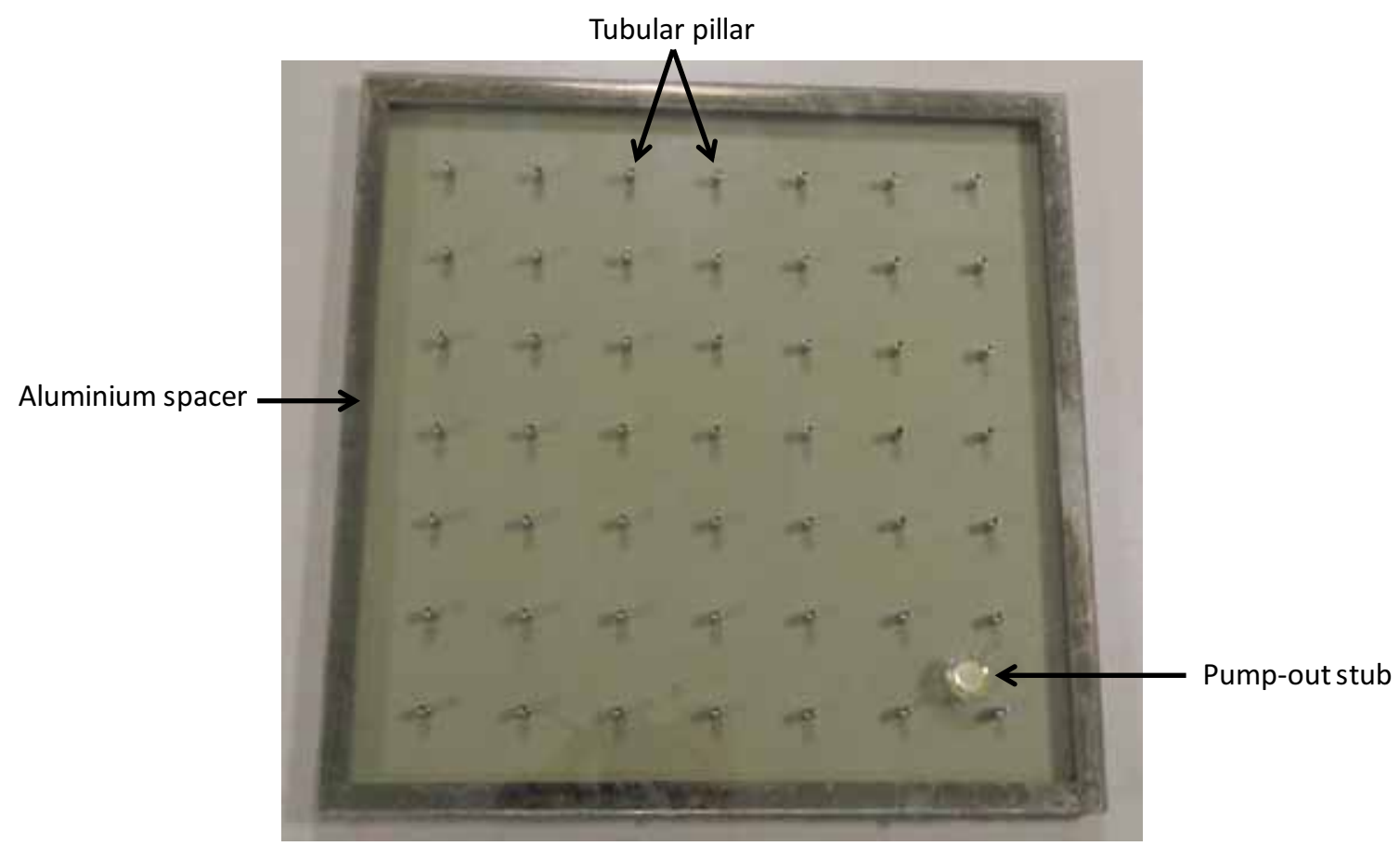

Fig. 3: Fabricated flat vacuum panel

\section{Thermal performance}

Heat transfer through the flat vacuum panel is measured using a guarded hot box calorimeter. The hot box calorimeter shown in Fig. 4 was designed in accordance with the British Standard methods for determining the thermal insulating properties (British Standard, 1987) and the international standard (ISO, 1996). The hot box calorimeter enables an accurate measurement of the overall heat flow through the flat vacuum panels which is contributed by pillar conduction, aluminium edge spacer conduction and radiation between the glass panes. The effects of conduction and convection due to any remaining gas in the evacuated cavity are also considered. The guarded hot box calorimeter comprises a hot and cold chamber separated by a mask wall. An opening is provided in the center of the mask wall where a frame is installed which can accommodate a vacuum panel of $0.4 \mathrm{~m}$ by $0.4 \mathrm{~m}$. For given air temperatures within the cold and hot chambers the hot box calorimeter allows an accurate measurement of the heat flow through the panel. The calculation method for the U-value of the test sample is reported elsewhere (Fang et al., 2006).

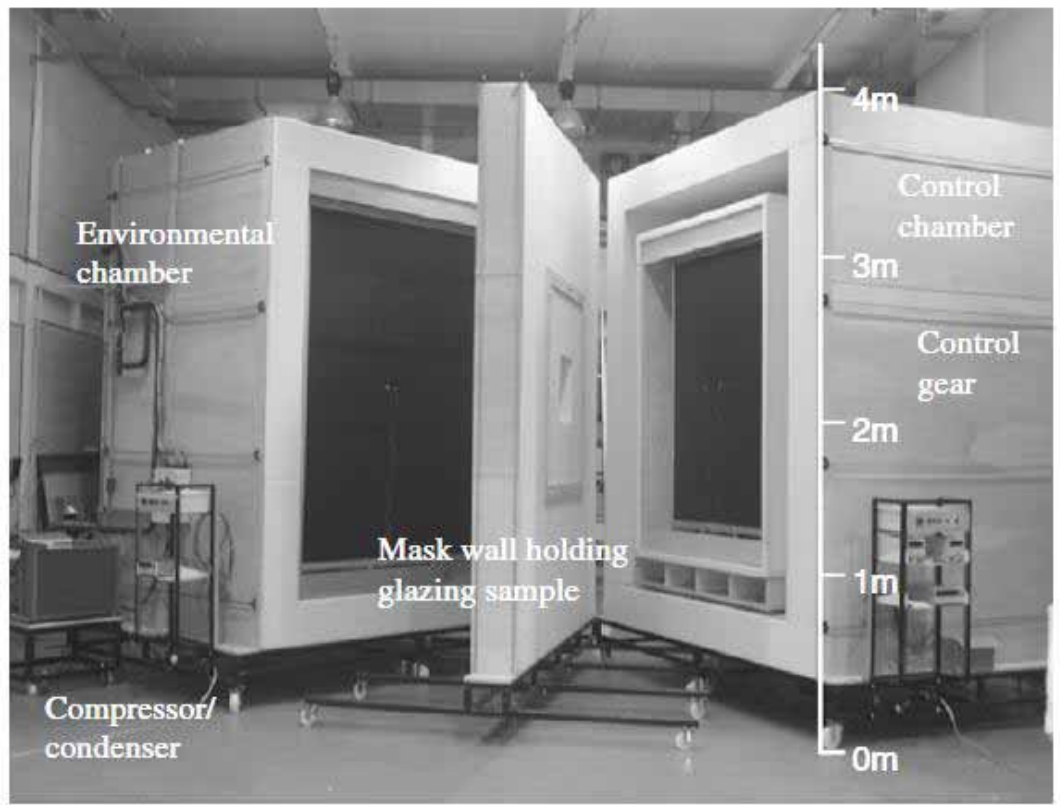

Fig. 4: Guarded hot box calorimeter available at the University of Ulster 
The air temperatures in the hot and cold chambers and heat transfer coefficients of the flat vacuum panels before and after the panels are evacuated are presented in Table 1 and Table 2 respectively.

Table 1: Air temperatures in the guarded hot box calorimeter and measured U-value of the flat vacuum panel before evacuation process

\begin{tabular}{|c|c|c|c|}
\hline \multirow{2}{*}{ Vacuum panel before evacuation } & \multicolumn{2}{|c|}{ Air temperature $\left({ }^{\mathbf{0}} \mathbf{C}\right)$} & Measured U-value $\left(\mathbf{W}^{\prime} \mathbf{m}^{-\mathbf{2}} \cdot \mathbf{K}^{\mathbf{- 1}}\right)$ \\
\cline { 2 - 4 } & Hot box & Cold box & Central glazing \\
\hline Sample 1 & 17.3 & -0.2 & 2.23 \\
\hline Sample 2 & 17.2 & -0.2 & 2.27 \\
\hline
\end{tabular}

The heat transfer coefficient of the panels prior to the evacuation of the cavity between the glass panes was $2.23 \mathrm{Wm}^{-2} \mathrm{~K}^{-1}$. This is similar to the thermal performance that would be expected from a conventional double glazing. By establishing a vacuum in the cavity, gaseous convective and conductive heat transfer was minimized resulting in a much lower heat transfer coefficient down to $0.86 \mathrm{Wm}^{-2} \mathrm{~K}^{-1}$ as measured for sample2.

Table 2: Air temperatures in the guarded hot box calorimeter and the measured $U$-value of the flat vacuum panel after evacuation process

\begin{tabular}{|c|c|c|c|}
\hline \multirow{2}{*}{ Vacuum panel after evacuation } & \multicolumn{2}{|c|}{ Air temperature $\left({ }^{\mathbf{0}} \mathbf{C}\right)$} & Measured U-value $\left(\mathbf{W}^{\prime} \mathbf{m}^{-\mathbf{2}} \cdot \mathbf{K}^{\mathbf{- 1}}\right)$ \\
\cline { 2 - 4 } & Hot box & Cold box & Central glazing \\
\hline Sample 1 & 18.8 & -0.3 & 0.95 \\
\hline Sample 2 & 19.1 & -0.3 & 0.86 \\
\hline
\end{tabular}

In flat vacuum panels, heat flux through the support pillars and the edge spacer can be detected using infrared thermography when the vacuum pressure is low enough to eliminate conductive and convective heat transfer through any residual gas (Zhao et al., 2007). In order to take an IR-image of a flat vacuum panel, a temperature difference of about $20^{\circ} \mathrm{C}$ is created between the two sides of the panel. The infrared camera used in this experiment is FLIR: B640. Fig. 5 is the IR-image of the panel which clearly demonstrates the heat flow through the pillars and the edge seal. This indicates that the level of vacuum is high enough to minimize gaseous convective and conductive heat transfer inside the panel.

Creating a temperature difference between the two sides of the vacuum panel during testing in the hot box calorimeter and during the infra-red thermography imposes differential thermal expansion stresses in the panels (Henshall et al., 2014). These tests did not impact on the integrity of the edge seal, however further work is required to determine the stress limits the panel can withstand. 


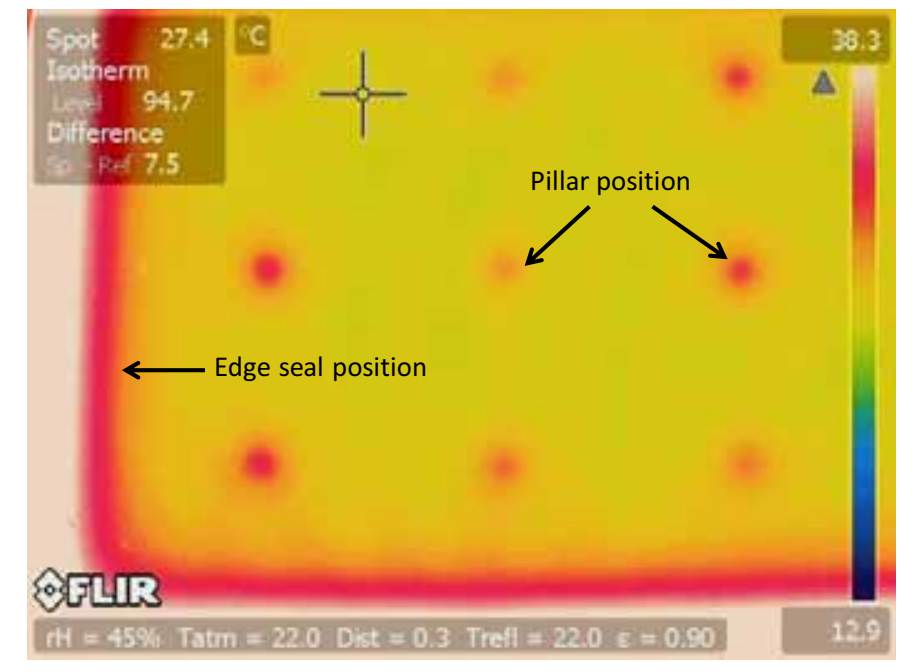

Fig. 5: IR-image of a flat vacuum panel

\section{Conclusion}

Flat vacuum panels were fabricated from two glass panes and an aluminum spacer using a low temperature edge sealing process. Using indium metal as a sealant and an ultrasonic soldering technique the seal between the glass panes and the aluminum spacer was formed in a vacuum oven. The metal seal was augmented with an epoxy resin to provide protection against moisture ingress and to provide additional structural rigidity. The edge seal is vacuum tight and hermetic and also strong enough to withstand stresses caused by atmospheric pressure and thermal expansion/contraction. Ageing tests are needed to be undertaken in order to evaluate the durability of the edge seal. However, during the evacuation and thermal characterization of the vacuum panels the edge seal did not fail.

The experimental characterization of the flat vacuum panels demonstrated excellent thermal performance with an overall heat transfer coefficient in the central panel region of $0.86 \mathrm{Wm}^{-2} \mathrm{~K}^{-1}$ with two low-e coatings (emittance of 0.16) on the interior glass surfaces. An increase in the panel size (which is the case in solar collectors) would reduce the influence of the edge seal on the overall thermal performance resulting in a lower heat transfer coefficient (Fang et al., 2007). If a solar absorber is incorporated in the vacuum panel the thermal insulation provided by the vacuum space will minimize the heat loss from the absorber resulting in an increase in the efficiency of the solar collector.

This research presents an accurate and reproducible fabrication method for flat vacuum panels which has the potential to be exploited in flat vacuum solar panel production line.

\section{Acknowledgement}

The support from the UK Engineering and Physical Sciences Research Council (EPSRC) through $\mathrm{EP} / \mathrm{K} 010107 / 1$ is gratefully acknowledged.

\section{References}

Benz, N., Beikircher, T., 1999. High efficiency evacuated flat-plate solar collector for process steam production. Solar Energy. 65, 111-118.

British Standards Institution, 1987. Determining Thermal Insulating Properties, Part 3. Test for Thermal Transmittance and Conductance, Section 3.1 Guarded Hot-box Method. British Standards Institution, Chiswick, London, UK.

Collins, R.E., Turner, G.M., Fischer-Cripps, A.C., Tang, J.Z., Simko, T.M., Dey, C.J., Clugston, D.A., Zhang, Q.C., Garrison, J.D., 1995. Vacuum glazing - A new component for insulating windows. Building and Environment. 30(4), 459-492.

Eaton, C., Blum, H., 1975. The use of moderate vacuum environments as a means of increasing the 
collection efficiencies and operating temperatures of flat-plate solar collectors. Solar Energy. 17,151-158.

Fang, Y., Eames P.C., Norton, B., Hyde, T.J., 2006. Experimental validation of a numerical model for heat transfer in vacuum glazing. Solar Energy. 80, 564-577.

Fang, Y., Eames, P.C., Norton, B., Hyde, T.J., Hewitt, N., 2007. The influence of edge seal and glazing size on the thermal performance of vacuum glazing. In: Proceeding of Heat SET 2007, April 2007, Chambery, France.

Henshall, P., Moss, R., Arya, F., Eames, P., Shire, S., Hyde, T., 2014. An evacuated enclosure design for solar thermal energy applications. In: Proceeding of Grand Renewable Energy 2014, July, Tokyo, Japan.

Hyde, T.J., Griffiths, P.W., Eames, P.C., Norton, B., 2000. Development of a novel low temperature edge seal for evacuated glazing. In: Proceedings of World Renewable Energy Congress VI, Brighton, UK. Oxford: Pergamon, pp. 271-274.

International Standard Organization, 1996. BS EN ISO 8990:1996. Thermal insulation- Determination of steady-state thermal transmission properties - Calibrated and guarded hot box.

Zhao, J.F., Eames, P.C., Hyde, T.J., Fang. Y., Wang., J.A., 2007. Modified pump-out technique used for fabrication of low temperature metal sealed vacuum glazing. Solar Energy. 81, 1072-1077.

Zoller, F., 1913. Hollow pane of glass. German Patent No. 387655. 